\title{
Lattice Displacement Calculations and Comparisons for Different Irradiation Facilities
}

$$
\begin{aligned}
& \text { H. T. Kerr } \\
& \text { E. J. Allen } \\
& \text { D. L. Reed }
\end{aligned}
$$




\section{DISCLAIMER}

This report was prepared as an account of work sponsored by an agency of the United States Government. Neither the United States Government nor any agency Thereof, nor any of their employees, makes any warranty, express or implied, or assumes any legal liability or responsibility for the accuracy, completeness, or usefulness of any information, apparatus, product, or process disclosed, or represents that its use would not infringe privately owned rights. Reference herein to any specific commercial product, process, or service by trade name, trademark, manufacturer, or otherwise does not necessarily constitute or imply its endorsement, recommendation, or favoring by the United States Government or any agency thereof. The views and opinions of authors expressed herein do not necessarily state or reflect those of the United States Government or any agency thereof. 


\section{DISCLAIMER}

Portions of this document may be illegible in electronic image products. Images are produced from the best available original document. 
Printed in the United States of America: Available from National Technical Information Service

U.S. Department of Commerce

5285 Port Royal Road, Springfield, Virginia 22161

Price: Printed Copy $\$ 4.00$; Microfiche $\$ 2.25$

This report was prepared as an account of work sponsored by the United States Government. Neither the United States nor the Energy Research and Development Administration, nor any of their employees, nor any of their contractors, subcontractors, or their employees, makes any warranty, express or implied, or assumes any legal liability or responsibility for the accuracy, completeness or usefulness of any information, apparatus, product or process disclosed, or represents that its use would not infringe privately owned rights. 


\title{
UC-77 - Gas-Cooled Reactor Technology
}

Contract No. W-7405-eng-26

\author{
Reactor Division
}

\section{LATTICE DISPLACEMENT CALCULATIONS AND COMPARISONS FOR DIFFERENT IRRADIATION FACILITIES}

\author{
H. T. Kerr E. J. Allen
}

D. L. Reed

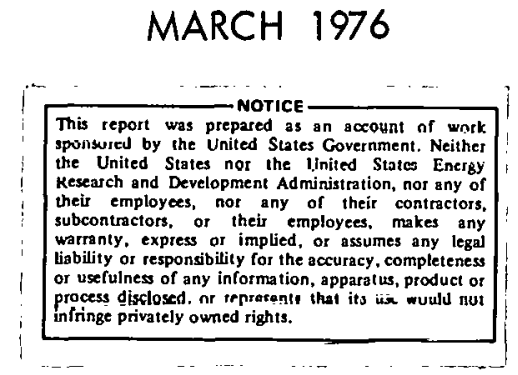

NOTICE: This document contains information of a preliminary nature and was prepared primarily for internal use at the Oak Ridge National Laboratory. It is subject to revision or correction and therefore doeo not represent a final report.

\author{
OAK RIDGE NATIONAL LABORATORY \\ Oak Ridge, Tennessee 37830 \\ operated by \\ UNION CARBIDE CORPORATION \\ for the \\ ENERGY RESEARCH AND DEVELOPMENT ADMINISTRATION
}




\section{THIS PAGE}

WAS INTENTIONALLY

LEFT BLANK 
CONTENTS

Page

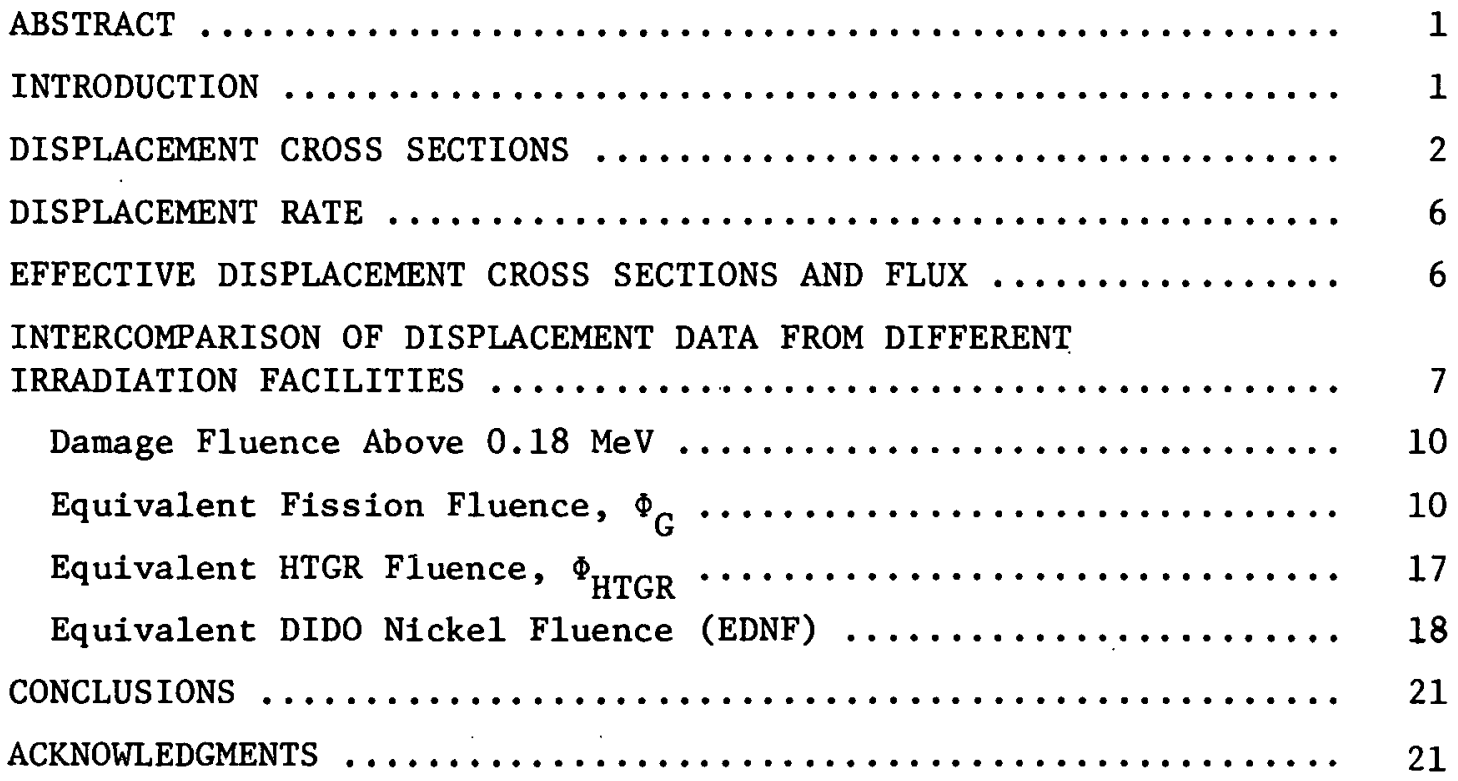




\title{
LATTICE DISPLACEMENT CALCULATIONS AND COMPARISONS FOR DIFFERENT IRRADIATION FACILITIES
}

\author{
H. T. Kerr E. J. Allen \\ D. L. Reed
}

\begin{abstract}
Descriptions of lattice displacement parameters are given, and methods for calculating displacement rates are described. Procedures are given for comparing displacement data from different irradiation facilities and effective damage fluence is defined. Values for effective graphite displacement cross sections and neutron fluxes are given for several irradiation facilities.
\end{abstract}

Key words: radiation damage, cross sections, graphite, in-pile tests, calculations, neutron flux, neutron spectra, HTGR.

\section{INTRODUCTION}

The mechanical and physical properties of all materials are altered by exposure to nuclear radiation. These property changes are usually degrading for most applications, and the irradiation damage is a major consideration in the design of nuclear systems. The mechanisms by which the damage occurs are varied and complex, but the damage mechanisms can be categorized by the initiating reactions. For example, the irradiation induced swelling of stainless steels, and the irradiation induced drift in thermocouples result from neutron induced isotopic transmutation reactions in the materiais. The irradiation induced swelling in graphite, however, results from atomic lattice displacements caused primarily by neutron scattering feactions with carbon atoms.

The magnitude and the rate of irradiation damage for a specific material in a particular irradiation facility are functions of both the nuclear properties of the material and the neutronic characteristics of the facility. For this reason, comparisons of irradiation damage data from different facilities must involve both the material properties and the neutronic characteristics of the facility. Previous attempts to compare irradiation damage solely on the basis of some arbitrary neutronics 
parameter (i.e., damage flux) were inaccurate and misleading. This memo identifies the factors involved in quantifying the displacement type of irradiation damage, and describes the procedures to be used for comparison of displacement damage data from different irradiation facilities. Graphite displacement damage is calculated for illustrative purposes, but the same methods can be applied to calculate displacement damage for any material.

\section{DISPLACEMENT CROSS SECTIONS}

The ncutron induced lattice displacement rate in a material depends on the probability of a neutron reaction occurring, $\sigma_{s}(E)$, and the number of lattice displacements resulting from each reaction, $p(E)$. Therefore, a displacement cross section can be defined as:

$$
\sigma_{D}(E)=\sigma_{s}(E) p(E)
$$

where

$$
\begin{aligned}
\sigma_{D}(E)= & \text { the displacement cross section; the displacement rate per } \\
& \text { unit neutron flux of energy } E \text {, } \\
\sigma_{S}(E)= & \text { the neutron reaction cross section, } \\
p(E)= & \text { the displacement weighing function. }
\end{aligned}
$$

The displacement cross section is a material dependent parameter. Neutron reaction cross sections are available from sources such as ENDF/B libraries.' The displacement weighing functions are derived from physics considerations of atomic interactions in matter. The displacement weighing function most widely used for interpretation of graph1te 1rradiation results was developed by Thompson and Wright. ${ }^{2}$ Values of the scattering cross section and Thompson and Wright welghing function for graphite are summarized in Table 1 . 'lhe displacement cross section for graph1te is plotted versus energy in Fig. 1.

${ }^{1}$ ENDF is the Evaluated Nuclear Data File and is the national reference set of evaluated cross section data.

${ }^{2}$. W. Thompson and S. B. Wright, "A New Damage Function for Predicting the Effect of Reactor Irradiation on Graphite in Different Neutron Spectra," J. Nucl. Mater. 16, 146-154 (1965). 
Table 1. Group-averaged values of the graphite scattering cross section and the Thompson and Wright displacement weighing function

\begin{tabular}{|c|c|c|c|}
\hline $\begin{array}{l}\text { Neutron } \\
\text { energy } \\
\text { group }\end{array}$ & $\begin{array}{l}\text { Upper } \\
\text { energy } \\
(\mathrm{MeV})\end{array}$ & $\begin{array}{l}\text { ENDF-IV elastic } \\
\text { scattering cross } \\
\text { section for } \\
\text { graphite (barns) }\end{array}$ & $\begin{array}{l}\text { Thompson and } \\
\text { Wright displace- } \\
\text { ment weighting } \\
\text { function }\end{array}$ \\
\hline 1 & 14.9 & 0.771 & 548.4 \\
\hline 2 & 13.5 & 0.785 & 540.6 \\
\hline 3 & 12.2 & 0.842 & 532.7 \\
\hline 4 & 11.1 & 0.673 & 524.7 \\
\hline 5 & 10.0 & 0.665 & 516.5 \\
\hline 6 & 9.05 & 0.773 & 508.2 \\
\hline 7 & 8.19 & 1.43 & 499.8 \\
\hline 8 & 7.41 & 0.740 & 491.5 \\
\hline 9 & 6.70 & 0.969 & 482.9 \\
\hline 10 & 6.07 & 0.924 & 474.1 \\
\hline 11 & 5.49 & 1.12 & 465.3 \\
\hline 12 & 4.97 & 1.41 & 456.3 \\
\hline 13 & 4.49 & 1.95 & 447.2 \\
\hline 14 & 4.07 & 2.15 & 437.6 \\
\hline 15 & 3.68 & 2.57 & 428.2 \\
\hline 16 & 3.33 & 1.80 & 418.7 \\
\hline 17 & 3.01 & 2.21 & 409.1 \\
\hline 18 & 2.73 & 1.65 & 399.4 \\
\hline 19 & 2.47 & 1.60 & 389.6 \\
\hline 20 & 2.23 & 1.90 & 379.7 \\
\hline 21 & 2.02 & 1.73 & 369.6 \\
\hline 22 & 1.83 & 1.85 & 359.4 \\
\hline 23 & 1.65 & 1.97 & 349.1 \\
\hline 24 & 1.50 & 2.10 & 338.7 \\
\hline 25 & 1.35 & 2.23 & 328.2 \\
\hline 26 & 1.22 & 2.35 & 317.6 \\
\hline 27 & 1.11 & 2.49 & 306.9 \\
\hline 28 & 1.00 & 2.62 & 296.1 \\
\hline 29 & 0.907 & 2.75 & 285.2 \\
\hline 30 & 0.821 & 2.87 & 274.2 \\
\hline 31 & 0.743 & 2.99 & 262.9 \\
\hline 32 & 0.672 & 3.11 & 251.5 \\
\hline 33 & 0.608 & 3.22 & 240.5 \\
\hline 34 & 0.550 & 3.32 & 229.2 \\
\hline 35 & 0.498 & 3.43 & 218.1 \\
\hline 36 & 0.450 & 3.52 & 207.3 \\
\hline 37 & 0.408 & 3.62 & 196.7 \\
\hline 38 & 0.369 & 3.70 & 186.3 \\
\hline 39 & 0.334 & 3.78 & 176.1 \\
\hline 40 & 0.302 & 3.86 & 166.2 \\
\hline
\end{tabular}


Table 1 (continued)

\begin{tabular}{|c|c|c|c|}
\hline $\begin{array}{l}\text { Neutron } \\
\text { energy } \\
\text { group }\end{array}$ & $\begin{array}{l}\text { Upper } \\
\text { energy } \\
(\mathrm{keV})\end{array}$ & $\begin{array}{l}\text { ENDF-IV elastic } \\
\text { scattering cross } \\
\text { section for } \\
\text { graphite (barns) }\end{array}$ & $\begin{array}{l}\text { Thompson and } \\
\text { Wright displace- } \\
\text { ment weighting } \\
\text { function }\end{array}$ \\
\hline 41 & 273.0 & 3.93 & 156.5 \\
\hline 42 & 247.0 & 4.00 & 147.0 \\
\hline 43 & 223.0 & 4.06 & 137.8 \\
\hline 44 & 202.0 & 4.12 & 128.8 \\
\hline 4.5 & 183,0 & 4.17 & 120.0 \\
\hline 46 & 166.0 & 4.22 & 111.5 \\
\hline 47 & 150.0 & 4.26 & 103.2 \\
\hline 48 & 136.0 & 4.30 & 95.2 \\
\hline 49 & 123.0 & 4.34 & 87.4 \\
\hline 50 & 111.0 & 4.40 & 74.8 \\
\hline 51 & 86.5 & 4.47 & 61.2 \\
\hline 52 & 67.4 & 4.53 & 49.7 \\
\hline 53 & 52.5 & 4.57 & 40.2 \\
\hline 54 & 40.9 & 4.61 & 32.3 \\
\hline 55 & 31.8 & 4.63 & 25.9 \\
\hline 56 & 24.8 & 4.65 & 20.7 \\
\hline 57 & 19.3 & 4.67 & 16.5 \\
\hline 58 & 15.0 & 4.68 & 13.1 \\
\hline 59 & 11.7 & 4.69 & 10.3 \\
\hline 60 & 9.12 & 4.70 & 8.0 \\
\hline 61 & 7.10 & 4.71 & 6.2 \\
\hline 62 & 5.53 & 4.71 & 4.8 \\
\hline 63 & 4.31 & 4.71 & 3.7 \\
\hline 64 & 3.35 & 4.72 & 2.9 \\
\hline 65 & 2.61 & 4.72 & 2.3 \\
\hline 66 & 2.03 & 4.72 & 1.8 \\
\hline 67 & 1.58 & 4.72 & 1.4 \\
\hline 68 & 1.23 & 4.72 & 1.1 \\
\hline 69 & 0.961 & 4.72 & 0.8 \\
\hline 70 & 0.749 & 4.73 & 0.6 \\
\hline 71 & 0.583 & 4.73 & 0.5 \\
\hline 72 & 0.454 & 4.73 & 0.4 \\
\hline 73 & 0.353 & 4.73 & 0.3 \\
\hline 74 & 0.275 & 4.73 & 0.2 \\
\hline 75 & 0.214 & 4.73 & 0.1 \\
\hline
\end{tabular}




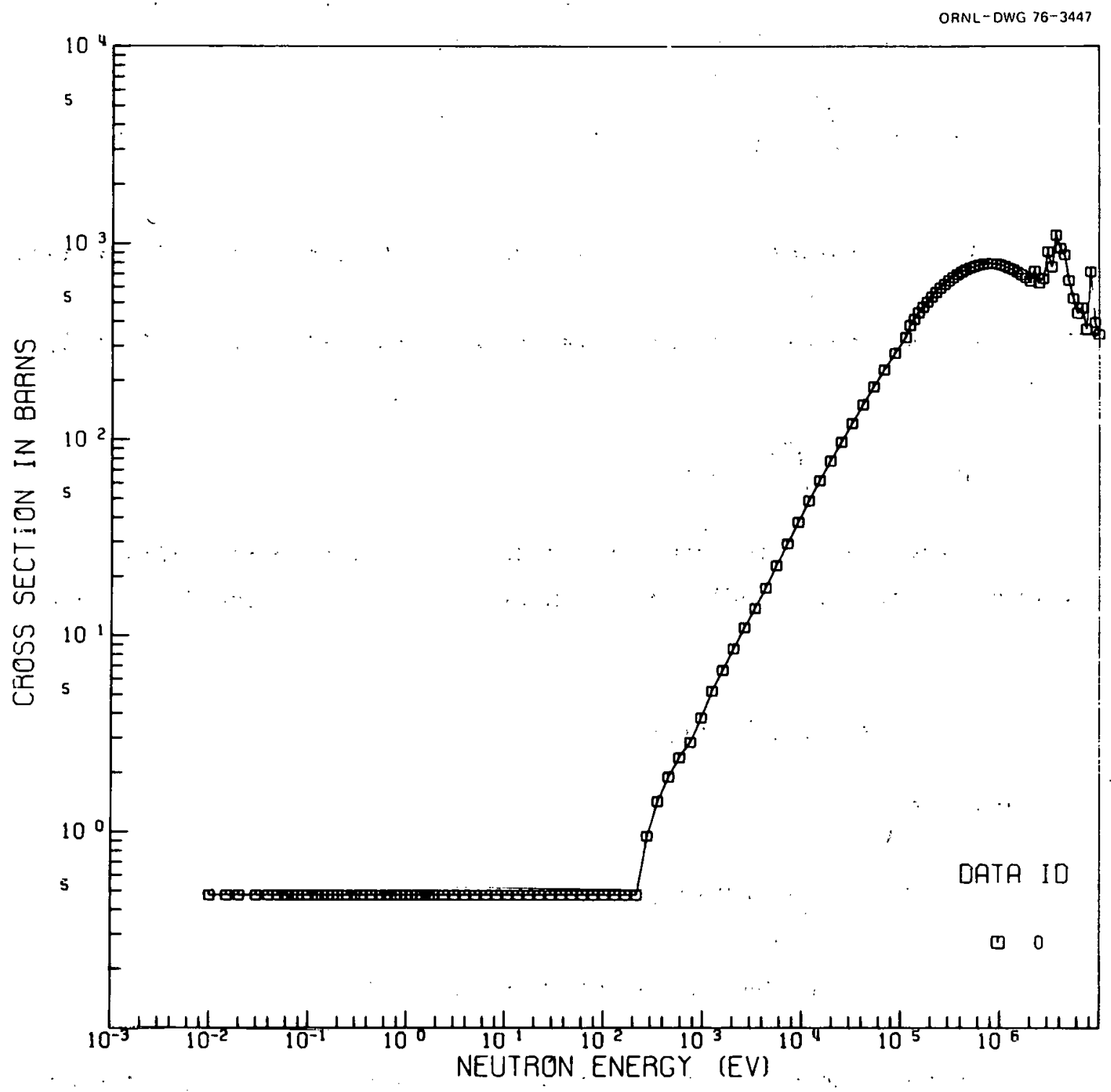

Fig. 1. Graphite displacement cross section. 
Each position in an irradiation facility has a unique time varying energy dependent neutron flux, $\phi(\vec{r}, E, t)$. The displacement rate for some material at each position can be expressed as:

$$
D(\bar{r}, t)=\int_{0}^{\infty} \sigma_{D}(E) \phi(\bar{r}, E, t) d E,
$$

where

$$
\begin{aligned}
\bar{D}(\bar{r}, t)= & \text { the displacement rate per target atom at prsition } \bar{x} \text { and } \\
& \text { time } t .
\end{aligned}
$$

'The average displacement rate for an irradiation interval of duration $T$ is then:

$$
D(\bar{r})=1 / T \int_{0}^{T} D(\bar{r}, t) d t
$$

If the energy dependence and magnitude of the neutron flux does not change during the irradiation, then $\phi(\bar{r}, E, t)=\phi(\bar{r}, E)$ and $D(\bar{r})=D(\bar{r}, t)$, or

$$
\bar{D}(\bar{r})=\int_{0}^{\infty} \sigma_{D}(E) \phi(x, E) d E
$$

or more simply

$$
D=\int_{0}^{\infty} \sigma_{D}(E) \phi(E) d E
$$

EFFECTIVE DISPLACEMENT CROSS SECTIONS AND FLUX

Although the displacement rale, $\bar{D}$, characterizes an irradiation position, effective cross sections and damage fluxes are sometimes convenient. The effective displacement cross section is defined by:

$$
\bar{\sigma}_{D}\left(E_{L}\right)=\frac{\int_{0}^{\infty} \sigma_{D}(E) \phi(E) d E}{\int_{E_{L}}^{\infty} \phi(E) d E}=\frac{D}{\bar{\phi}\left(E_{L}\right)},
$$


where

$$
\begin{aligned}
\bar{\sigma}_{D}\left(E_{L}\right)= & \text { the effective displacement cross section for cutoff energy } \\
& E_{L}, \\
D= & \text { displacement rate per target atom, } \\
\bar{\sigma}\left(E_{L}\right)= & \text { the integral neutron flux above the cutoff energy } E_{L}, \\
& \text { or the damage flux above } E_{L} .
\end{aligned}
$$

Note that

$$
\bar{\sigma}_{D}\left(E_{L}\right) \bar{\phi}\left(E_{L}\right)=D \equiv \int_{0}^{\infty} \sigma_{D}(E) \phi(E) d E
$$

is satisfied regardless of the energy $E_{L}$. Values of neutron fluxes and effective displacement cross sections for graphite are given in Table 2 for various reactor facilities and neutron energy spectra.

A special case arises when the neutron fission spectrum, $\chi(E)$, is used for the flux. In this case, a fission spectrum average displacement cross section, $\bar{\sigma} x$, is obtained:

$$
\bar{\sigma}_{x}=\frac{\int_{0}^{\infty} \sigma_{D}(E) x(E) d E}{\int_{0}^{\infty} x(E) d E} .
$$

This cross section is used as a comparative standard in ref. 3.

\section{INTERCOMPARISON OF DISPLACEMENT DATA FROM DIFFERENT IRRADIATION FACILITIES}

Some basis is frequently needed to facilitate comparisons of irradiation damage from different facilities. The most physically significant characteristics to compare would be the displacement rates for the facilities and the total displacements for a particular sample or irradiation time. These can be estimated using the displacement cross sections of a particular material and the neutron flux of the facility. If the displacement cross sections are not readily available, a suitably defined effective

3"Recommended Practice for Reporting Neutron Dosimetry Results on Graphite," ASTM Standards 4 45, E525 (1974). 
Table 2. Effective graphite displacement cross sections

\begin{tabular}{|c|c|c|c|c|c|c|}
\hline \multirow{2}{*}{$\begin{array}{l}\text { Neutron flux } \\
\text { spectrum }\end{array}$} & \multicolumn{2}{|c|}{$E_{L}=5.0 \times 10^{-4} \mathrm{eV}$} & \multicolumn{2}{|c|}{$E_{L}=0.052 \mathrm{MeV}$} & \multicolumn{2}{|c|}{$E_{L}=0.183 \mathrm{MeV}$} \\
\hline & $\begin{array}{c}\bar{\phi}\left(E_{\bar{L}}\right) \\
\left(\mathrm{n} / \mathrm{cm}^{2} \sec \times 10^{15}\right)\end{array}$ & $\begin{array}{l}{ }_{D}\left(E_{L}\right) \\
\text { (barns) }\end{array}$ & $\begin{array}{c}\bar{\phi}\left(E_{L}\right) \\
\left(n / \mathrm{cm}^{2} \sec \times 10^{15}\right)\end{array}$ & $\begin{array}{l}\overline{\bar{\sigma}}_{D}\left(E_{L}\right) \\
\text { (barns) }\end{array}$ & $\begin{array}{c}\overline{\phi\left(E_{L}\right)} \\
\left(\mathrm{n} / \mathrm{cm}^{2} \sec \times 10^{15}\right)\end{array}$ & $\begin{array}{l}\bar{\sigma}_{D}\left(E_{L}\right) \\
\text { (barns) }\end{array}$ \\
\hline 1 & $10^{-15}$ & 169.9 & $0.258 \times 10^{-15}$ & 658.5 & $0.190 \times 10^{-15}$ & 894.6 \\
\hline 2 & $10^{-15}$ & 717.2 & $0.994 \times 10^{-15}$ & 721.6 & $0.963 \times 10^{-15}$ & 744.4 \\
\hline 3 & 0.257 & 85.56 & 0.032 & 685.3 & 0.028 & 797.9 \\
\hline 4 & 0.0649 & 63.15 & 0.0060 & 685.8 & 0.0052 & 781.3 \\
\hline 5 & 1.0 & 786.3 & 0.421 & 679.5 & 0.354 & 809.1 \\
\hline 6 & 1.0 & 278.5 & 0.408 & 683.1 & 0.346 & 804.8 \\
\hline 7 & 6.1 & 166.4 & 1.48 & 685.4 & 1.26 & 806.0 \\
\hline 8 & 3.0 & 138.8 & 0.624 & 666.8 & 0.495 & 840.5 \\
\hline 9 & 5.9 & 200.0 & 1.72 & 686.8 & 1.47 & 803.9 \\
\hline 10 & 3.1 & 614.6 & 2.91 & 655.8 & 2.34 & 812.6 \\
\hline
\end{tabular}

${ }^{\text {a Spectrum }}$

Neutron flux spectzun descriptions

Nornalized large HTGR spectrum (Don Matthews, GA)

Nornalized ${ }^{233} \mathrm{U}$ fission spectrum

Neutron flux 2.51 in. into ORR poolside

Neutron flux 5.65 in. into ORR poolside

Neutron flux at center oĩ E-3 facility of ORR

Neutron flux at edge of E-3 facility of ORR

Neutron flux of HFIR target

Neutron flux of HFIR RB-3 facility

Neutron Elux of HFIR PTP facility

Neutron Elux for horizontal midplane of row $Z$ of EBR-2 
neutron damage fluence can be used. Damage fluences are widely used as a comparative basis.

Consider two irradiation facilities, A and B, each with a characteristic energy dependent neutron flux, $\phi_{A}(E)$ and $\phi_{B}(E)$. Then for a given material, 'effective displacement cross sections and fluxes are given by:

$$
\bar{\sigma}_{D}^{A}\left(E_{L}\right)=\frac{\int_{0}^{\infty} \sigma_{D}(E) \phi_{A}(E) d E}{\int_{E_{L}}^{\infty} \phi_{A}(E) d E}=\frac{D_{A}}{\bar{\phi}_{A}\left(E_{L}\right)},
$$

and

$$
\vec{\sigma}_{D}^{B}\left(E_{L}\right)=\frac{\int_{0}^{\infty} \sigma_{D}(E) \phi_{B}(E) d E}{\int_{E_{L}}^{\infty} \phi_{B}(E) d E}=\frac{D_{B}}{\bar{\phi}_{B}\left(E_{L}\right)} .
$$

If the number of displacements in $A$ is equal to the number of displacements in $B$, then:

$$
\bar{\sigma}_{D}^{A}\left(E_{L}\right) \bar{\phi}_{A}\left(E_{L}\right) t_{A}=\bar{\sigma}_{D}^{B}\left(E_{L}\right) \bar{\phi}_{B}\left(E_{L}\right) t_{B}=\text { tota1 displacements, }
$$

where

$$
\begin{aligned}
t_{A} & =\text { Irradiation time in facility } A, \\
t_{B} & =\text { irradiation time in facility } B, \\
\bar{\phi}_{A}\left(E_{L}\right) t_{A} & =\text { effective damage fluence in facility } A \text { above } E_{L}, \\
\bar{\phi}_{B}\left(E_{L}\right) t_{B} & =\text { effective damage fluence in facility. } B \text { above } E_{L} .
\end{aligned}
$$

Note that equal damage fluence, $\bar{\phi}_{A}\left(E_{L}\right) t_{A}$ and $\bar{\phi}_{B}\left(E_{L}\right) t_{B}$, will produce equal displacements only under the special circumstance $\bar{\sigma}_{D}{ }^{A}\left(E_{L}\right)=\bar{\sigma}_{D}{ }^{B}\left(E_{L}\right)$. However, the effective cross sections are generally not equal so that equal damage fluences do not generally result in equal total displacements.

For many years, graphite displacement data from reactor facilities have been compared on the basis of neutron fluences above $E_{L}=0.18 \mathrm{MeV}$ without regard for differences in effective displacement cross sections. The justification for initiating this practice resulted from the following observations. The high energy portion of the neutron energy spectra in 
most reactor facilities is very similar and is also responsible for most displacements in graphite. Therefore, by choosing the right cutoff energy, $E_{L}$, the effective displacement cross sections for most reactor spectra would have nearly the same value, and intercomparisons could be based solely on fluence above $E_{L}$. The cutoff energy of $0.18 \mathrm{MeV}$ was selected on this basis in some previous evaluation.

\section{Damage Fluence Above $0.18 \mathrm{MeV}$}

A recent evaluation has been made of the effective graphite displacement cross section, $\bar{\sigma}_{D}\left(E_{L}\right)$, at several cutoff energies, $E_{L}$, for a variety of reactor spectra of current interest. Figure 2 shows $\bar{\sigma}_{D}\left(E_{L}\right)$ versus $E_{L}$ for these spectra. (These energy spectra are also referred to in Table 2 and are plotted in Figs. 3 through 12.) As can be seen, $\bar{\sigma}_{D}\left(E_{L}\right)$ has nearly the same value for all the neutron energy spectra when $E_{L}=0.18 \mathrm{MeV}$. Therefore, when $\mathrm{E}_{\mathrm{L}}=0.18 \mathrm{MeV}$ is used as the cutoff energy, relative damage fluences will be nearly equivalent to relative displacement number. Note, however, that the $\bar{\sigma}_{D}\left(E_{L}\right)$ are even closer when $E_{L}=0.052 \mathrm{MeV}$. This suggests that the basis for comparing graphite displacement data from different facilities should be neutron fluences with $E_{L}=0.052 \mathrm{MeV}$ rather than $\mathrm{E}_{\mathrm{L}}=0.18 \mathrm{MeV}$.

The observation that the damage fluence above $0.18 \mathrm{MeV}$ is nearly proportional to the number of atoms displaced originally led to the practice of comparing graphite displacement data from different facilities solely on the basis of neutron fluence above $0.18 \mathrm{MeV}$. However, more detailed comparisons should incorporate all available information, and calculations of displacement rates and total displacements should be made. Displacement damage data from different irradiation facilities can be compared on the basis of these two characteristics.

$\underline{\text { Equivalent Fission Fluence, } \Phi_{G}}$

Other displacement damage characteristics have been defined for use in comparison of damage in graphite. The "equivalent fission fluence for damage in graphite" $\Phi_{G}$ is defined as follows: 


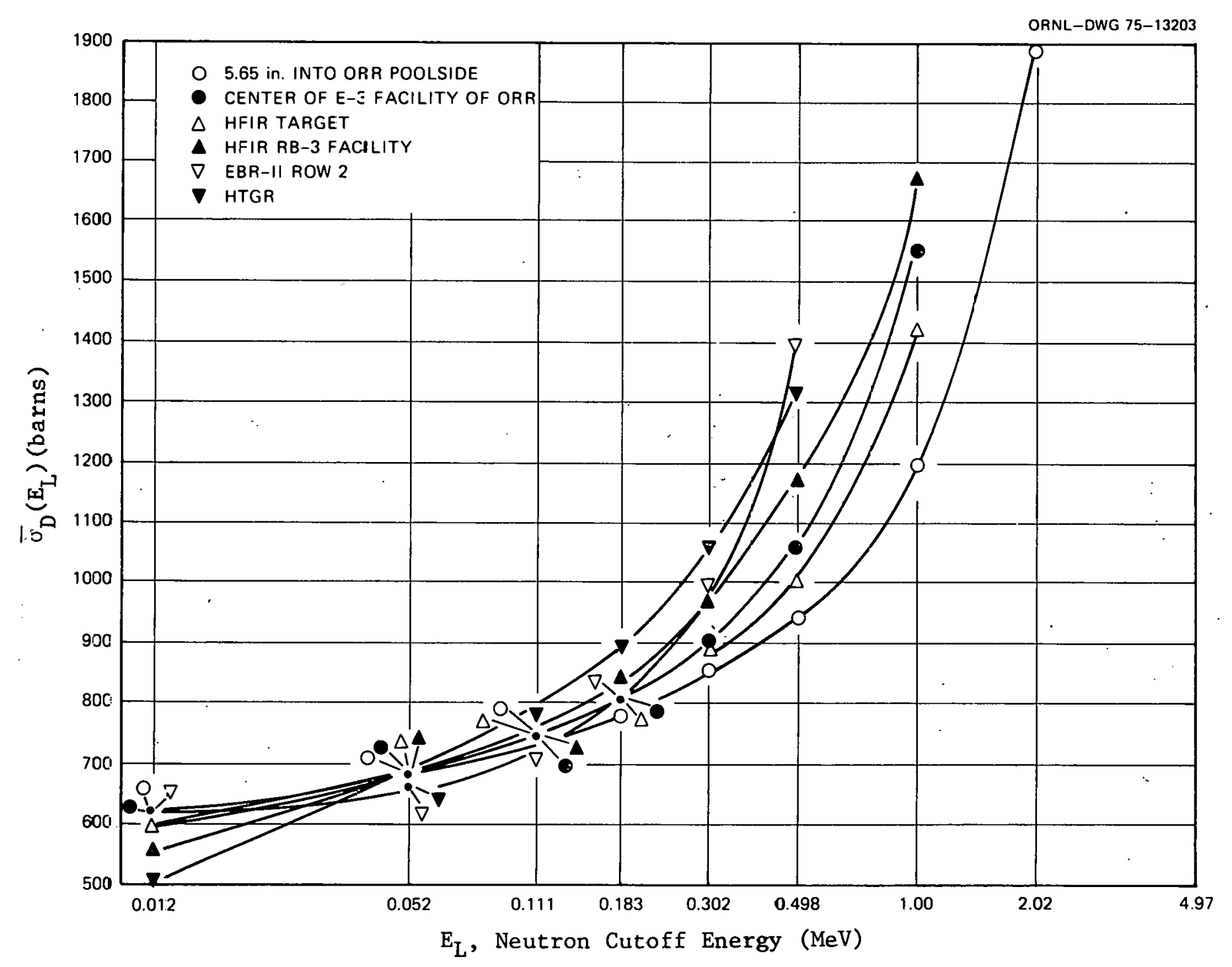

Fig. 2. Effective graphite displacement cross section versus cutoff energy for various reactor spectra. 


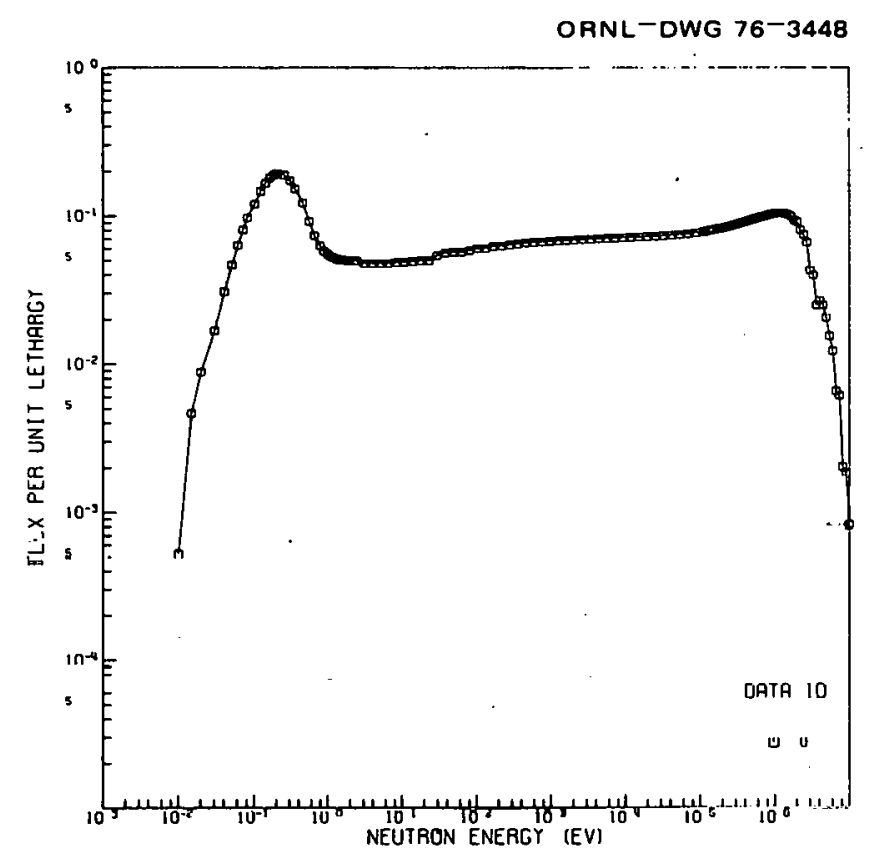

F1g. 3. HTGR spectrum (GA).

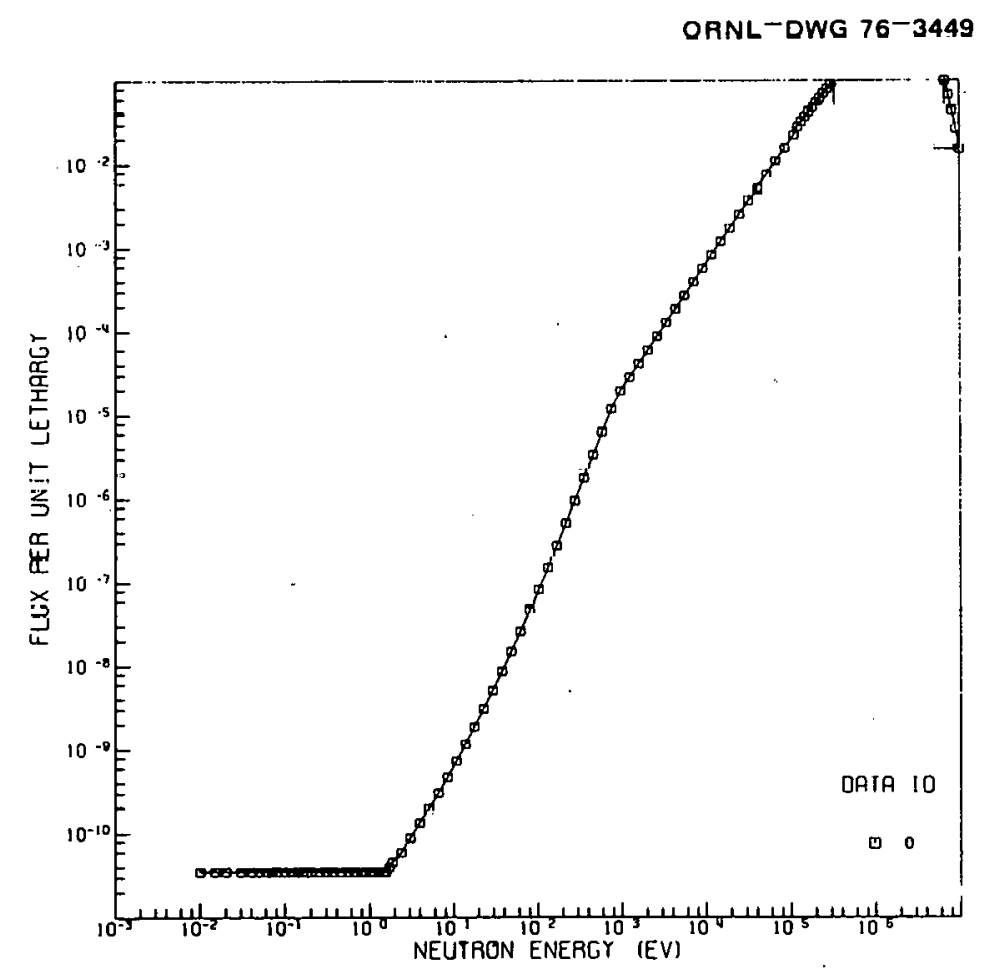

Fig. 4. ${ }^{233} \mathrm{U}$ fission spectrum (ENDF-IV). 


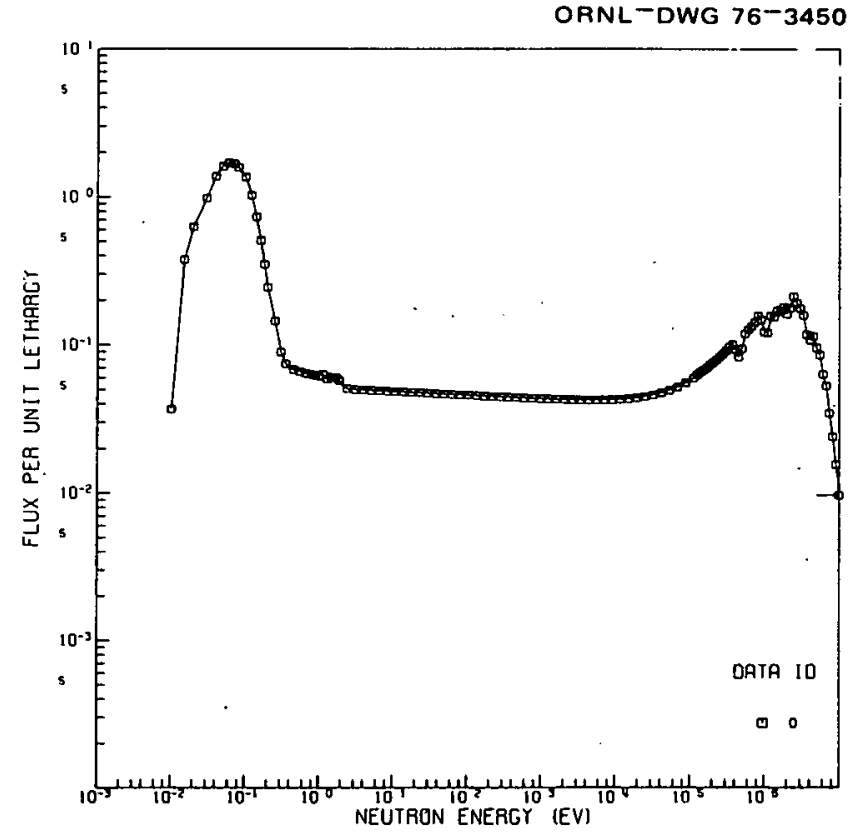

Fig. 5. Calculated neutron flux spectrum 2.51 in. into $O R R$ poolside.

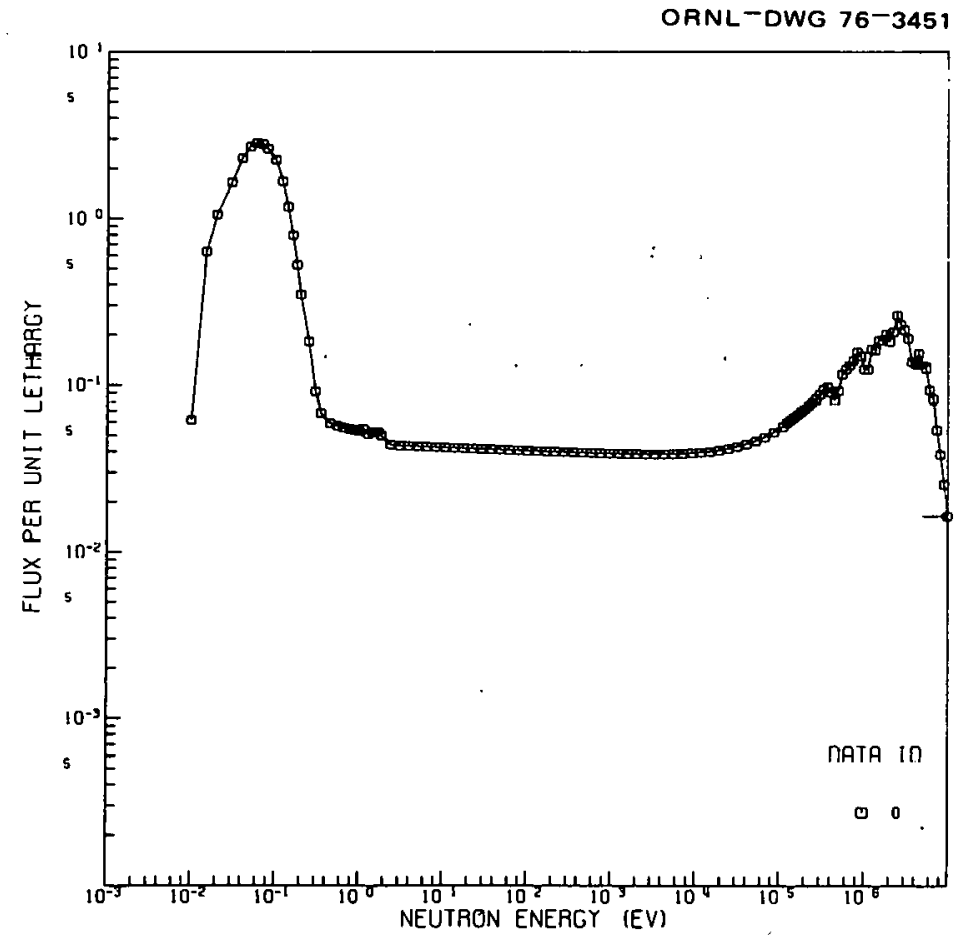

Fig. 6. Calculated neutron flux spectrum 5.65 in. into ORR poolside. 


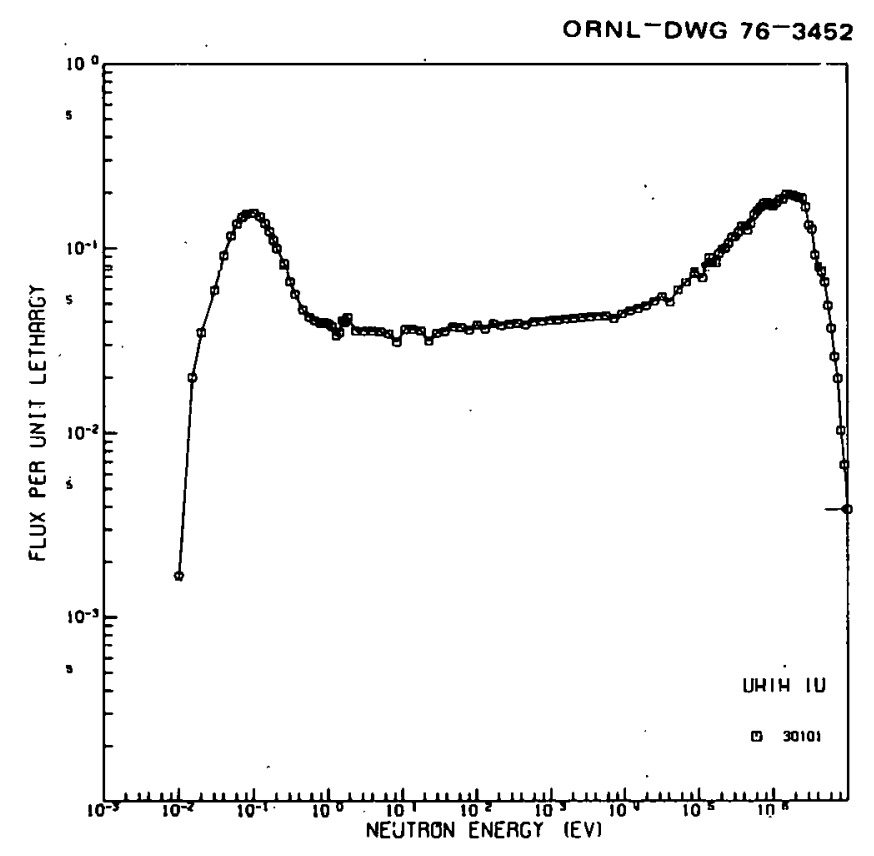
of ORR.

Fig. 7. Calculated neutron flux spectrum at center of E-3 facility

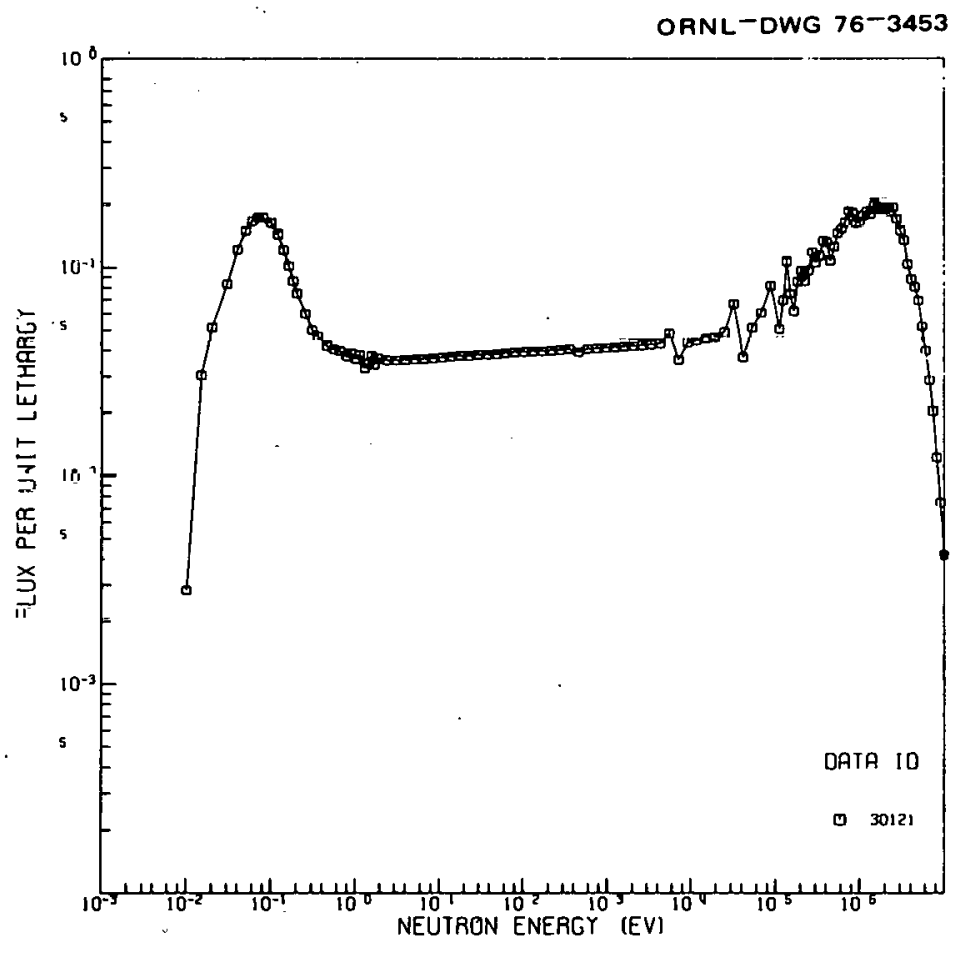

Fig. 8. Calculated neutron flux spectrum at edge of E-3 facility of ORR. 


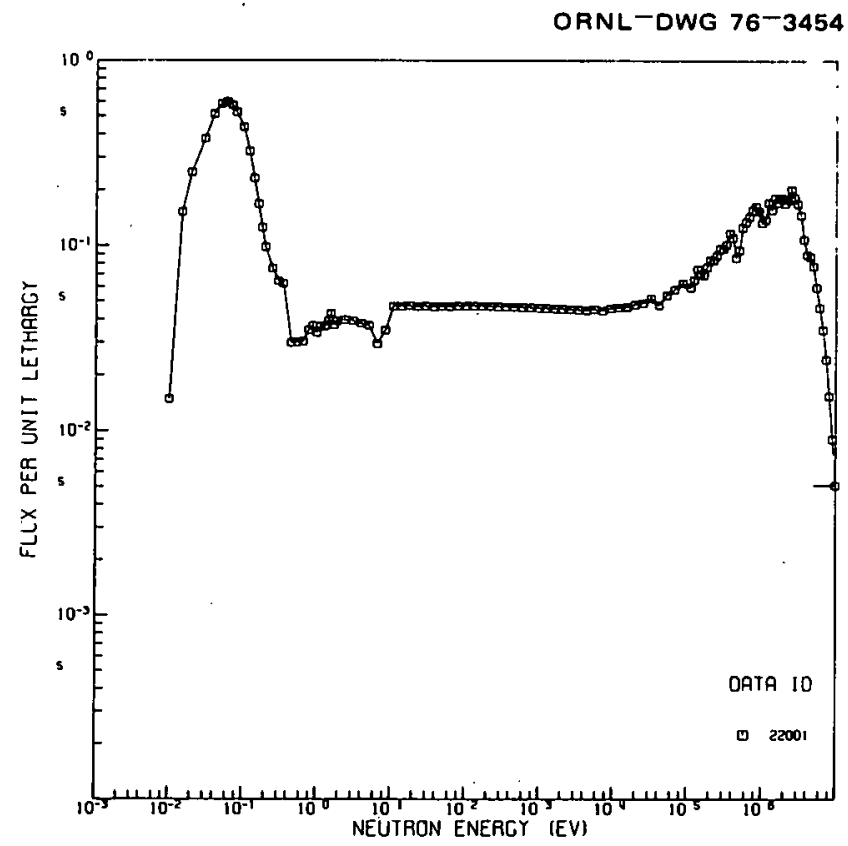

Fig. 9. Calculated neutron flux spectrum in HFIR target.

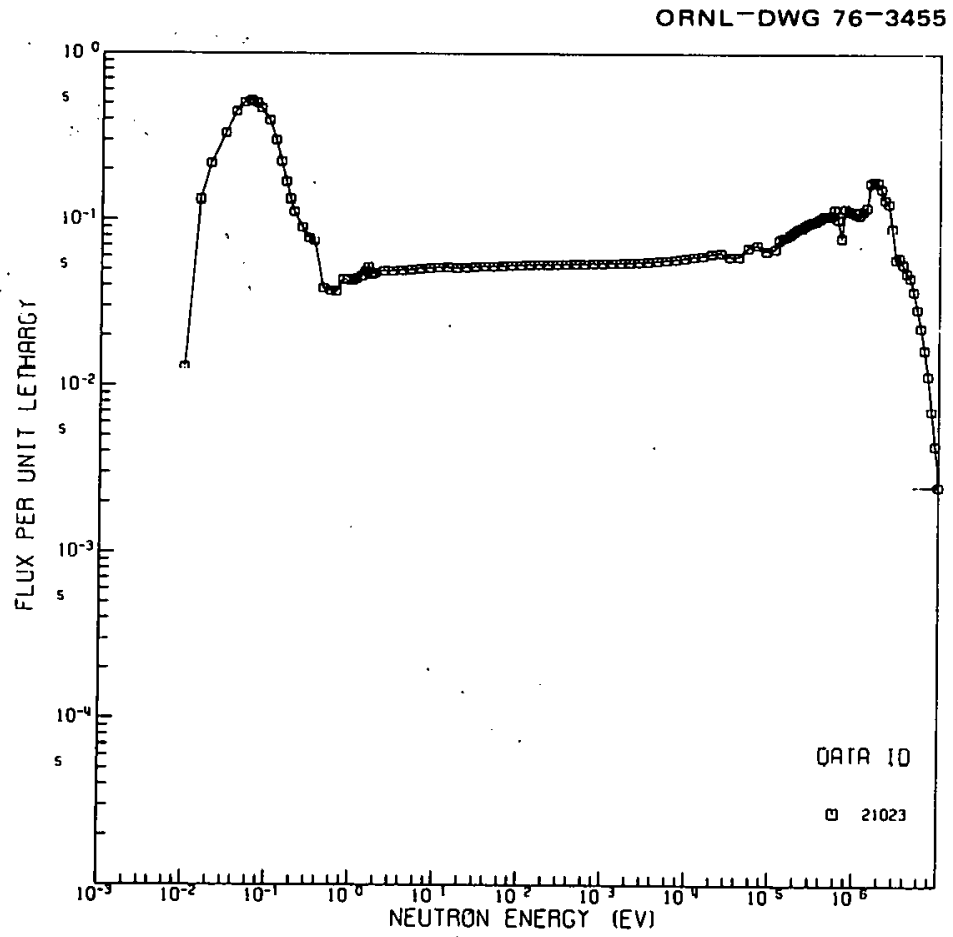

Fig. 10. Calculated neutron flux spectrum in RB-3 facility of HFIR. 


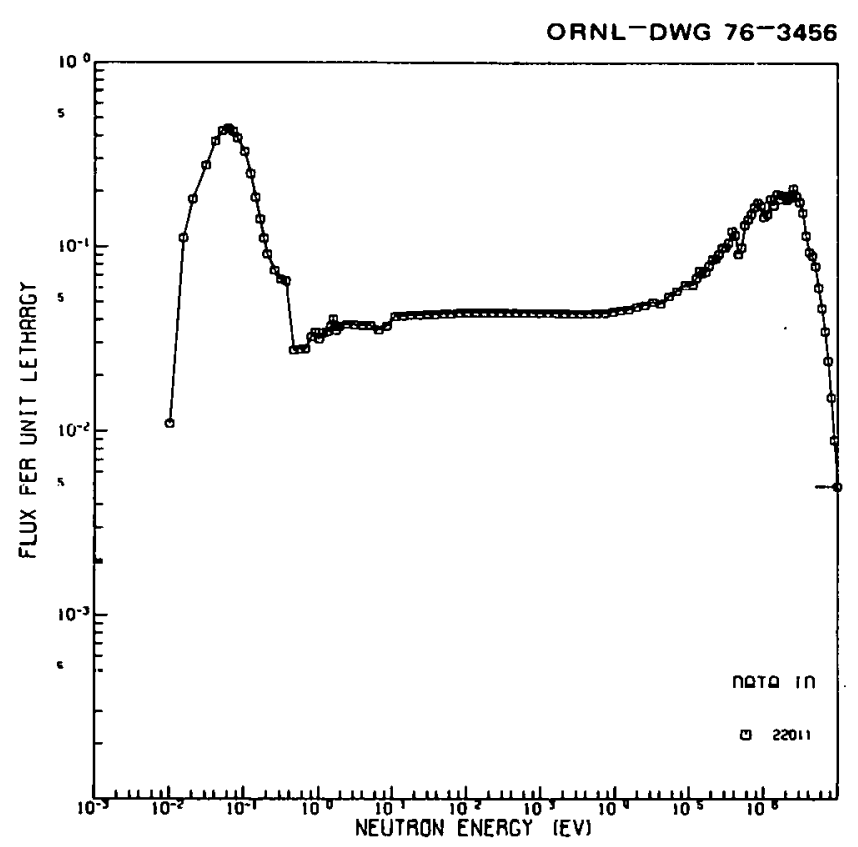

Fig. 11. Calculated neutron flux spectrum in HFIR PTP facility.

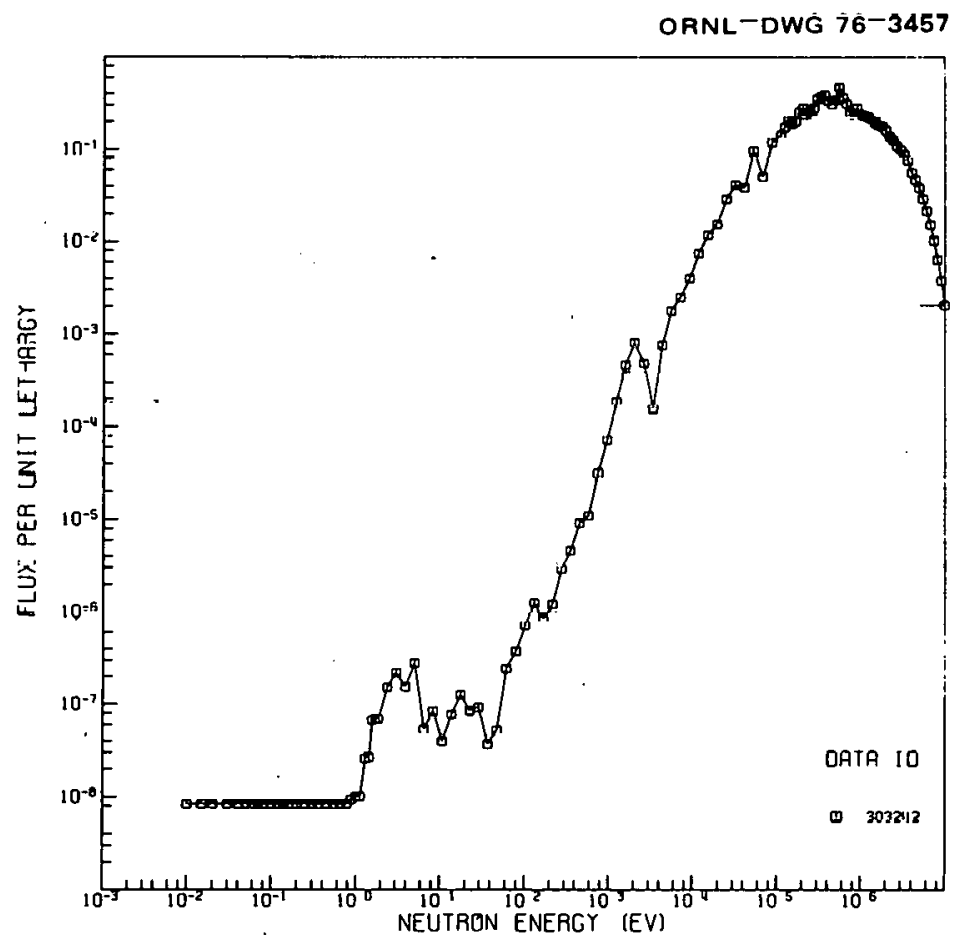

Fig. 12. Calculated neutron flux spectrum in row 2 HMP of EBR-II. 


$$
\Phi_{G}=\frac{\int_{t_{1}}^{t_{2}} \int_{0}^{\infty} \sigma_{D}(E) \phi(E, t) d E d t}{\int_{0}^{\infty} \sigma_{D}(E) x(E) d E / \int_{0}^{\infty} \chi(E) d E},
$$

or

$$
\Phi_{G}=\frac{\text { total displacements }}{\bar{\sigma}_{\mathbf{x}}},
$$

where

$$
\begin{aligned}
t_{2}-t_{1} & =\text { duration of the irradiation test } \\
\bar{\sigma}_{x} & =\text { fission spectrum average cross section, } \\
\phi(E, t) & =\text { neutron flux in the irradiation test. }
\end{aligned}
$$

Physically, $\Phi_{G}$ is the fluence required in a fission spectrum to produce the number of displacements that occurred in a particular irradiation test. The "equivalent fission fluence" is widely used and is described in detail in Ref. 3.

\section{Equivalent HTGR Fluence, $\Phi_{\text {HTGR }}$}

Another parameter, the "equivalent HTGR fluence for damage in graphite" is defined as follows:

$$
\begin{aligned}
\Phi\left(E_{L}\right)_{H T G R} & =\frac{\int_{0}^{\infty} \int_{t_{1}}^{t_{2}} \sigma_{D}(E) \phi(E, t) d t d E}{\int_{0}^{\infty} \sigma_{D}(E) \phi(E)_{H T G R} d E / \int_{E_{L}}^{\infty} \phi(E)_{H T G R} d E}, \\
\Phi\left(E_{L}\right)_{H T G R} & =\frac{\text { total displacements }}{\bar{\sigma}\left(E_{L}\right)_{H T G R}},
\end{aligned}
$$

where

$$
\begin{aligned}
\bar{\sigma}_{\mathrm{HTGR}}= & \text { effective displacement cross section for an HTGR spectrum } \\
& \text { above energy } \mathrm{E}_{\mathrm{L}}, \\
\phi(E, t)= & \text { neutron flux in the irradiation test, } \\
\Phi\left(E_{\mathrm{L}}\right)_{\mathrm{HTGR}}= & \text { equivalent HTGR fluence for damage in graphite for } \\
& \text { energy above } \mathrm{E}_{\mathrm{L}} .
\end{aligned}
$$


Physically, $\Phi\left(E_{L}\right)_{H T G R}$ is the neutron fluence above energy $E_{L}$ which a specimen must experience in a reference HTGR flux spectrum to produce the same number of atom displacements that occurred in a particular irradiation test. This convention is particularly useful for reporting graphite irradiation data from various test facilities in a form directly applicable to HTGRs.

Considerable graphite test data have previously been reported in terms of neutron fluences in the various test facilities, and intercomparisons of these data require translation of the reported fluences into a common parameters such as the equivalent HTGR fluence above some cutoff energy $E^{*}$. This translation can be accomplished by defining a conversion factor $f_{B}\left(F_{L}\right)$ as follows:

$$
\Phi\left(E^{*}\right)_{H T G R}=\frac{\bar{\sigma}\left(E_{L}\right)_{R}}{\bar{\sigma}\left(E^{*}\right)_{H T G R}} \times \Phi\left(E_{L}\right)_{R}=f_{R}^{*}\left(E_{L}\right) \times \Phi\left(E_{L}\right)_{R},
$$

where

$$
\begin{aligned}
R= & \text { subscript denoting a particular irradiation test, } \\
t_{R}^{*}\left(E_{L}\right)= & \bar{\sigma}\left(E_{L}\right)_{R} / \bar{\sigma}\left(E^{\wedge}\right)_{H T G R}, \\
E^{*}= & \text { specified cutoff energy for HTGR spcctrum (not necessarily } \\
& \text { the same as } \left.\bar{E}_{L}\right) .
\end{aligned}
$$

The other terms are as previously defined. Note that the conversion factor is a ratio of effective displacement cross sections and is, therefore, dependent on both the cutoff energy $E_{L}$ and the neutron energy spectra used to obtain the effective cross sections. The neutron energy spectrum in a given irradiation test is dependent on both the irradiation facility and the test capsule composition, so that a unique conversion factor must be defined for each irradiation test. However, for practical purposes a conversion factor can be defined for similar capsules in a given facility. Some typical values of interest to the HTGR program are given in Table 3.

\section{Equivalent DIDO Nickel Fluence (EDNF)}

A convention commonly used in Europe for correlating irradiation damage in graphite is the "Equivalent DIDO Nickel Flux (EDNF)." This convention was developed because many of the early irradiations for studying 
Table 3. Factors to convert damage fluences in test facilities to equivalent HTGR fluences $a$ above $0.183 \mathrm{MeV}$

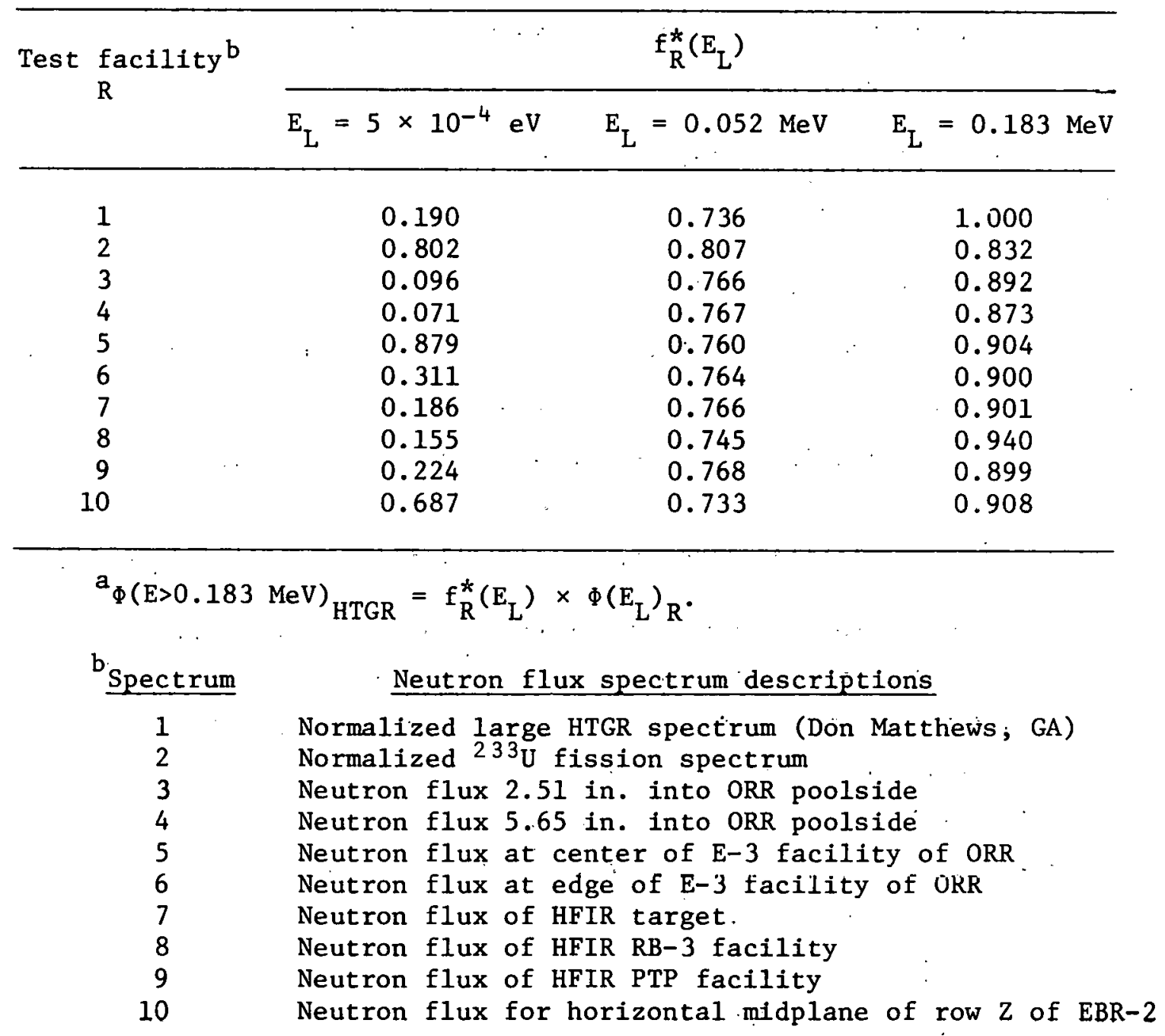


graphite damage were made in the DIDO reactor, and this reactor was selected as a conventent reference neutron source. The EDNF is defined as the nickel flux in DIDO which will produce the same graphite damage as the reactor under consideration; the Equivalent DIDO Nickel Dose (EDND) is the time integrated EDNF.

A nickel flux, $\phi_{N 1}$, can be defined for a reactor with a neutron flux spectrum $\phi(E)$ by:

$$
\phi_{\mathrm{N} 1}=\int_{0}^{\infty} \sigma_{\mathrm{Ni}}(\mathrm{E}) \phi(\mathrm{E}) \mathrm{dE} / \hat{\sigma}_{\mathrm{Ni}}=\mathrm{RR}_{\mathrm{Ni}} / \hat{\sigma}_{\mathrm{N} 1}
$$

where

$$
\begin{aligned}
\phi_{\mathrm{Ni}}= & \text { the ulckel Ilux in the reactor, } \\
\sigma_{\mathrm{Ni}}(E)= & \text { the differential cross section for the }{ }^{58} \mathrm{Ni}(\mathrm{n}, \mathrm{p}) \text { reaction, } \\
\phi(E)= & \text { the neutron flux spectrum in the reactor, } \\
\hat{\sigma}_{\mathrm{Ni}}= & \text { the fission spectrum averaged cross section for the }{ }^{58} \mathrm{Ni}(\mathrm{n}, \mathrm{p}) \\
& \text { reaction, } \\
\mathrm{RR}_{\mathrm{Ni}}= & \text { the atomic reaction rate for the }{ }^{58} \mathrm{Ni}(\mathrm{n}, \mathrm{p}) \text { reaction. }
\end{aligned}
$$

The ${ }^{58} \mathrm{Ni}(\mathrm{n}, \mathrm{p})$ reaction rate can be determined experimentally or can be calculated if the neutron flux spectrum is known. Several years ago, the neutron flux spectrum was determined for a specific position in a selected DIDO reactor configuration. This spectrum was then used to calculate a DIDO nickel flux $\phi_{\mathrm{Ni}}^{*}$ using the preceding definition. The same DIDO spectrum was used to calculate an atom displacement rate for graphite, $\mathrm{N}_{\mathrm{d}}^{*}$, in the DIDO facility by:

$$
\mathrm{N}_{\mathrm{d}}^{*}=\int_{0}^{\infty} \sigma_{\mathrm{d}}(E) \phi^{*}\left(F_{1}\right) d F .
$$

where

$$
\begin{aligned}
& \sigma_{d}(E)=\text { the graphite displacement cross section, } \\
& \phi^{*}(E)=\text { the specified DIDn spectrum. }
\end{aligned}
$$


An effective graphite displacement cross section based on the DIDO nickel flux could then be defined:

$$
\bar{\sigma}_{\mathrm{d}}^{*} \equiv \frac{\mathrm{N}_{\mathrm{d}}^{*}}{\phi_{\mathrm{Ni}}^{*}} .
$$

Results from graphite irradiations in other facilities can be related to results from the DIDO irradiations. For example, if the graphite displacement rate, $\mathrm{N}_{\mathrm{d}}^{\mathrm{R}}$, for some reactor is known, then the equivalent DIDO nickel flux for this reactor can be expressed as:

$$
\operatorname{EDNF}=\frac{\mathrm{N}_{\mathrm{d}}^{\mathrm{R}}}{\bar{\sigma}_{\mathrm{d}}^{*}} .
$$

When the graphite displacement rate in the reactor is not known, the reactor spectrum can be assumed identical to that in DIDO. Then a nickel flux, $\phi_{\mathrm{Ni}}^{\mathrm{R}}$, can be experimentally determined for the reactor and used to estimate the graphite displacement rate in the reactor:

$$
\mathrm{N}_{\mathrm{d}}^{\mathrm{R}} \simeq \phi_{\mathrm{Ni}}^{\mathrm{R}} \bar{\sigma}_{\mathrm{d}}^{*}
$$

However, this approach is limited by the assumed spectral similarity.

$$
\text { CONCLUSIONS }
$$

Several cuñentiuns fur Intercomparison of graphite irradiation data have been described. In each of these conventions there is an implied knowledge of the detailed neutron flux spectrum in the neutron energy range where graphite displacements occur. Unfortunately, the neutron spectra in most irradiation facilities are not well known and, regardless of the convention used, intercomparisons are limited by uncertainties in the neutron spectra.

\section{ACKNOWLEDGMENTS}

The authors are gratelul to Don Matthews (GAC) for his assistance and suggestions relating to this work, and to $\mathrm{M}$. $\mathrm{H}$. Wilson for typing the report. 
THIS PAGE

WAS INTENTIONALLY

LEFT BLANK 


\author{
ORNL/TM-5269 \\ UC-77 - Gas-Cooled Reactor
Technology
}

Internal Distribution
1. H. L. Adair
2-6. E. J. Allen
7. T. E. Cole
8. J. A. Conlin
9. J. H. Coobs
10. W. E. Cooper
11. W. B. Cottrel1
12. F. L. Culler
13. W. P. Eatherly
14. J. R. Engel
15. K. Farrell
16. G. G. Fee
17. R. M. Flanders
18. M. H. Fontana
19. T. A. Gabriel
20. Uri Gat
21. M. J. Goglia
22. H. W. Hoffman
23. F. J. Homan
24. C. R. Hyman
25. J. D. Jenkins
26. M. J. Kania
27. F.B.K. Kam
28-30. P. R. Kasten
31-35. H. T. Kerr
36. R. W. Kno11
37. T. B. Lindemer
38. E. L. Long, Jr.
39. A. W. Longest
40. A. L. Lotts
41. R. E. MacPherson
42. W. J. McCarthy

43. H. E. McCoy

44. S. R. McNeany

45. B. H. Montgomery

46. H. A. Parker

47. H. Postma

48. G. L. Ragan

49. D. L. Reed

50. J. E. Rushton

51. J. P. Sanders

52. J. L. Scott

53. R. L. Senn

54. Myrtleen Sheldon

55. I. Spiewak

56. J. H. Swanks

57. J. J. Taylor

58. W. E. Thomas

59. K. R. Thoms

60. M. L. Tobias

61. D. B. Trauger

62. K. H. Valentine

63. T. N. Washburn

64. G. D. Whitman

65. F. W. Wiffen

66. W. J. Wilcox

67. J. W. Woods

68. R. M. Young

69. ORNL Patent Office

70-71. Central Research Library

72. Document Reference Section

73-75. Laboratory Records Department

76. Laboratory Records (RC)

\title{
Externa1 Distribution
}

77-78. Director, Division of Nuclear Research and Application, ERDA, Washington, D.C. 20545

79. Director, Reactor Division, ERDA-ORO

80. Research and Technical Support Division, ERDA-ORO

81-247. Technical Information Center, ERDA [For distribution as shown in TID-4500 under category UC-77, Gas-Cooled Reactor Technology (25 copies - NTIS)] 